\title{
Enteric-Coated Aspirin and the Risk of Gastrointestinal Side Effects: A Systematic Review
}

\author{
Hanan Muzeyin Kedir \\ Eskinder Ayalew Sisay (D) \\ Alfoalem Araba Abiye \\ Department of Pharmacology and \\ Clinical Pharmacy, School of Pharmacy, \\ Collage of Health Sciences, Addis Ababa \\ University, Addis Ababa, Ethiopia
}

Correspondence: Hanan Muzeyin Kedir Department of Pharmacology and Clinical Pharmacy, School of Pharmacy, Collage of Health Sciences, Addis Ababa University, P.O.Box: II76, Addis Ababa, Ethiopia $\mathrm{Tel}+251912275828$

Email hanuaymu@gmail.com
Introduction: Aspirin appeared as a medicine to deal with aches and inflammation, but due to its antiplatelet properties, it has evolved into a drug mainly used to avert cardiovascular disease. Regardless of its therapeutic uses, the limiting aspect for aspirin use has been its affiliation with gastrointestinal (GI) toxicity, classifying from acute mucosal damage to GI problems and death.

Objective: The aim of this systematic review is to address the question regarding the ECA effect on the gastric mucosa.

Methods: A systematic search of the literature was conducted in the PubMed electronic databases from April 10th to April 23rd, 2020. Eligibility has been set, and based on those criteria, initially a total of 637 results were obtained, from these 58 of them were not written in English. Then, 168 articles which were free from duplication were screened and all the included articles were RCTs published after 2000. Based on these, final number of articles included on this review was 6 .

Results: Data were obtained from 6 published articles which reported on 15,621 participants. The reports were from 3 different countries. Most of the studies revealed that entericcoated aspirin (ECA) treatment was not an effective mechanism against GI protection. ECA administration with omeprazole can hugely reduce the incidence of endoscopic GI damage compared to the impact of ECA used alone. Even short-term administration of a low dose of ECA was significantly associated with an apparent small bowel injury.

Conclusion: ECA treatment is not an effective mechanism against GI protection, and it is highly associated with small bowel injury. So the coating does not reduce risk of GI complications.

Keywords: enteric coated, aspirin, gastrointestinal, side effects

\section{Introduction}

Initially aspirin was as a medicine to deal with aches and inflammation, but due to its antiplatelet properties, it has evolved into a drug mainly used to avert cardiovascular disease. ${ }^{1}$ Long-term use of low-dose aspirin, often described as 75-325 mg daily, is for primary and secondary prevention of cardiovascular disease such as myocardial infarction. ${ }^{2-5}$ Regardless of its therapeutic uses, the limiting aspect for aspirin use has been its affiliation with gastrointestinal (GI) toxicity, classifying from acute mucosal damage to GI problems and death. ${ }^{6-8}$

Aspirin is a non-steroidal anti-inflammatory drug that inhibits cyclooxygenase, an important enzyme in the biosynthesis of prostaglandins 1 . The mechanisms by which aspirin causes GI mucosal damage are thought to be by both direct topical injury on the epithelium and mainly, a systemic effect associated to prostaglandin 
depletion. ${ }^{9,10}$ Different research has mentioned the risk factors for aspirin-induced GI complications, such as higher aspirin dose, advanced age, history of peptic ulcer disease, use of combinations of non-steroidal antiinflammatory drugs and concomitant use of drugs such as steroids or anticoagulants. ${ }^{11,12}$

There are mechanisms used to diminish aspirinassociated GI injury, like reducing the dose of aspirin ${ }^{6,13}$ and use of aspirin with a gastro-protective agents like proton pump inhibitors. ${ }^{11}$ Adjustments also have been made in attempts to make aspirin greater tolerable in the GI tract, ${ }^{14}$ such as designing enteric-coated aspirin (ECA) with cellulose or silicon which resists disintegration in the stomach, permitting aspirin to dissolve specifically in the duodenum, the place the $\mathrm{pH}$ is more alkaline, or using buffering agents, such as calcium carbonate, magnesium oxide, or magnesium carbonate, which lower the hydrogen ion concentration in the GI tract. ${ }^{1}$

Previously published systematic reviews indicated that there is a reduction of gastric mucosal injury with ECA formulation. ${ }^{15}$ Whereas, recent studies demonstrate that using of enteric-coated formulations of aspirin may also no longer influence the incidence rate of clinically relevant GI outcomes. ${ }^{14}$ In terms of frequency or severity of damage, ECA no longer provided any advantage over plain aspirin and did not minimize the chance of peptic ulcer formation and GI bleeding, ${ }^{16,17}$ because the effect of both plain and ECA on upper GI bleeding is particularly systemic. ${ }^{18}$ Hence, the aim of this systematic review was to address the question regarding the ECA effect on the gastric mucosa.

\section{Methods}

\section{Information Sources}

A systematic search of the literature was conducted in the PubMed electronic databases from April 10-April 23 2020. In the process the following key terms were used as text and MESH words for the search in the electronic database: "Enteric Coated", "Aspirin", "Gastrointestinal" and 'Side Effects'. In this review all published randomized control trials that reported on the impact of ECA on GI mucosa were included.

\section{Eligibility Criteria}

In the current systematic review, randomized clinical trials were only used to strengthen the quality of evidence. Studies written in non-English language, unpublished documents, studies which used a study design other than randomized clinical trial and also articles which are published before 2000 were excluded from this review. The authors separately screen out the identified articles.

\section{Search Strategy}

Initially 637 articles were identified through systematic search from PubMed electronic database. From those articles 58 were not written in English language. After screening the titles and abstracts, around 168 articles were identified that were free from duplication. From those only 14 articles were randomized control trials. Finally, we excluded articles published earlier than 2000, this meant we had 6 articles for final analysis.

\section{Data Collection Process}

Method of data extraction from reports was done independently from the selected articles.

\section{Key Outcomes}

The main outcome of interest was the safety of ECA regarding its GI side effects.

\section{Risk of Bias}

The validity of selected randomized clinical trials checked through the adequacy of randomization and allocation and the blinding techniques. Furthermore, the roles of health care providers, principal investigators and data collectors. Finally, how the outcome was assessed as well as the magnitude of loss to follow-up.

\section{Summary Measures}

In addition to descriptive analysis (frequency and percentage, means, standard deviations [SD] and medians), hazard ratio and the corresponding two-sided 95\% was used to describe the outcomes of the trials. Chi-square test and $t$ - test were also used to analyze the data.

\section{Results Study Selection}

A total of 637 articles were identified during the initial search. After screening the titles and abstracts using the predefined inclusion and exclusion criteria, 58 articles were removed because they were not written in English. Then 168 articles were screened for duplication and only 14 of these were evaluated in full text. Finally, 6 RCTs ${ }^{19-24}$ published after 2000 were included in this review. 
The data was obtained from 15,621 (male=10,283; female $=5338$ ) participants, which has been collected from 3 different countries. Among 6 articles, 3 of them were from the USA, 2 from Japan, and 1 from Germany. Europe contributed to $77 \%$ of the study participants, while the USA enrolled $22.8 \%$ participants (see Figure 1).

\section{Study Characteristics}

Concerning result presentation, one trial presented its data by comparing ECA with placebo. Another study compared geranylgeranylacetone (GGA) with placebo in subjects taking low-dose ECA and another RCT compared to placebo, low-dose ECA, rofecoxib + low-dose ECA, and ibuprofen. In one trial, PA32540 (ECA $325 \mathrm{mg}$ and immediate-release omeprazole $40 \mathrm{mg}$ ) and ECA $325 \mathrm{mg}$ was compared. Another trial dealt with the issue of the long-term GI safety of PA32540 (ECA $325 \mathrm{mg}$ and immediate-release omeprazole $40 \mathrm{mg}$ ), and the final trial studied the effects of misoprostol on patients who developed gastric ulcers while undergoing low-dose ECA therapy.

All the collected trials were published between 2004 and 2018. Among the 6 studies, 4 of them were a multicenter studies. The studies were done with varying numbers of participants. Thelongest follow up was six years and the shortest was seven days. All studies were done using RCT study design and more than half of the study participants in this review were classified as old age population (above 50 years) 8287 (53.1\%). Four out of 6 studies had shown a comparison, mainly between ECA alone and a combination with gastroprotective agents or a placebo (see Table 1).

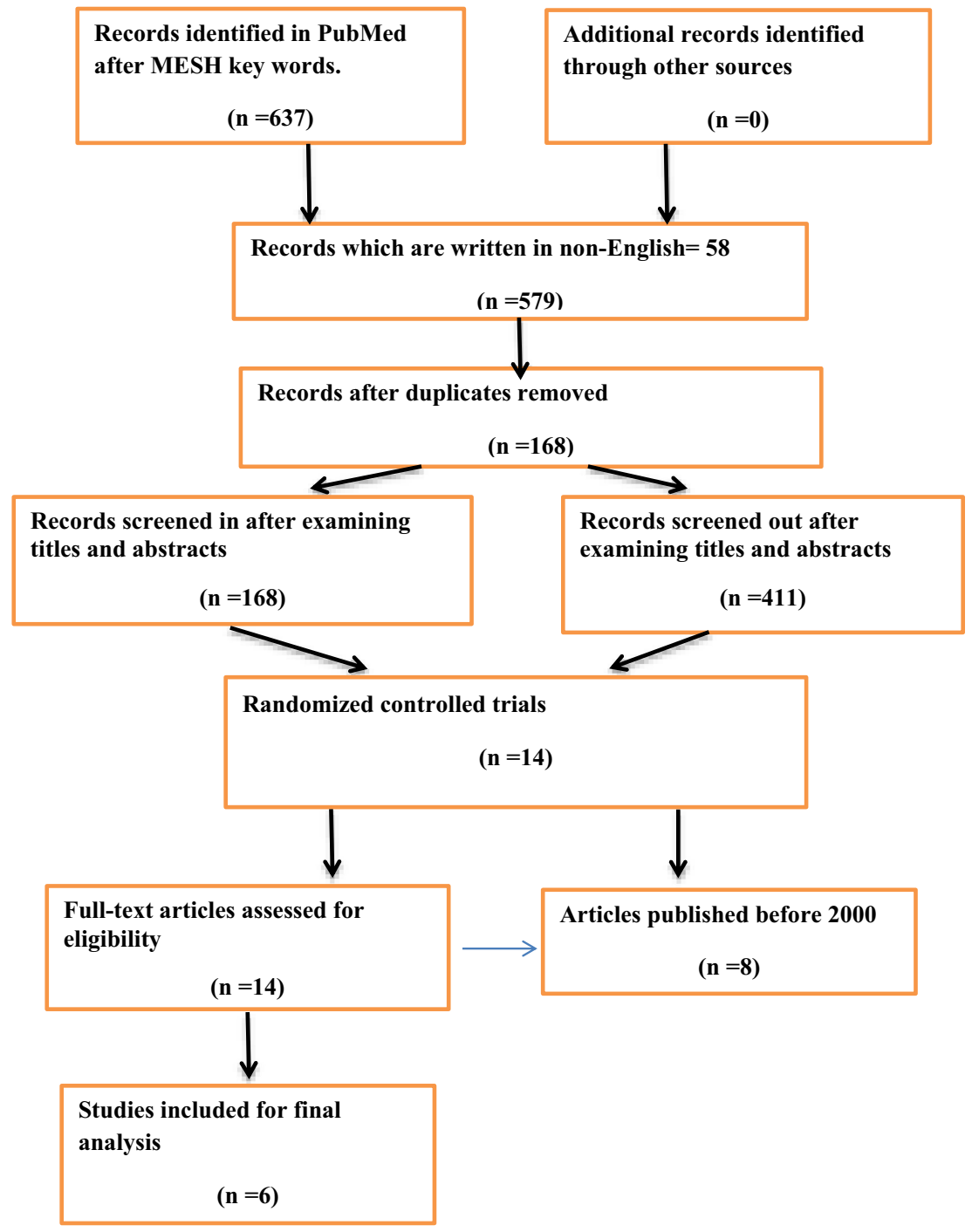

Figure I Study selection flow diagram. 
Table I Summary of RCTs Included in the Analysis

\begin{tabular}{|c|c|c|c|c|c|c|c|c|}
\hline S.N & Year & Country & Center & Subjects & Study Purpose & Interventions & Outcome & $\begin{array}{l}\text { No of } \\
\text { Studies } \\
\text { Included } \\
\text { in Each } \\
\text { Trial }\end{array}$ \\
\hline 1 & 2004 & USA & 82 & 1615 & $\begin{array}{l}\text { Risk of ulcer in low dose } \\
\text { aspirin and its interaction } \\
\text { with COX-2 selective } \\
\text { inhibitor }\end{array}$ & $\begin{array}{l}81 \mathrm{mg} \text { enteric-coated } \\
\text { aspirin, } 81 \mathrm{mg} \text { ECA plus } \\
25 \mathrm{mg} \text { rofecoxib, } 800 \mathrm{mg} \\
\text { ibuprofen or placebo. }\end{array}$ & Incidence of ulcer. & [30] \\
\hline 2 & 2010 & Japan & I & 20 & $\begin{array}{l}\text { Assessing GGA would reduce } \\
\text { aspirin induced } \mathrm{Gl} \text { injury }\end{array}$ & $\begin{array}{l}\text { I00mg ECA with either } \\
\text { GGA plus rabeprazole } \\
\text { or placebo }\end{array}$ & $\begin{array}{l}\text { Side effects such } \\
\text { as Gl damage }\end{array}$ & [35] \\
\hline 3 & 2008 & Japan & I & 11 & $\begin{array}{l}\text { Analyzing ulcerogenic effect } \\
\text { of low dose of ECA on small } \\
\text { bowel }\end{array}$ & $\begin{array}{l}\text { Low dose of ECA either } \\
\text { with misoprostol or PPI }\end{array}$ & $\begin{array}{l}\text { Damages to the } \\
\text { small intestine }\end{array}$ & {$[15]$} \\
\hline 4 & 2014 & USA & 153 & 1049 & $\begin{array}{l}\text { To compare ECA vs PA } 32540 \\
\text { against upper GI injury }\end{array}$ & $\begin{array}{l}\text { PA32540 or } 325 \mathrm{mg} \text { of } \\
\text { ECA }\end{array}$ & Upper Gl damage & [28] \\
\hline 5 & 2018 & Germany & 501 & 12,546 & $\begin{array}{l}\text { Investigate the efficacy of } \\
100 \mathrm{mg} E C A \text { vs placebo in } \\
\text { prevention of myocardial } \\
\text { infarction }\end{array}$ & $\begin{array}{l}\text { Either } 100 \mathrm{mg} \text { ECA or } \\
\text { placebo }\end{array}$ & $\begin{array}{l}\text { Gl complaints } \\
\text { including } \\
\text { dyspepsia, GERD } \\
\text { and upper } \\
\text { abdominal pain. }\end{array}$ & [22] \\
\hline 6 & 2016 & USA & 44 & 379 & $\begin{array}{l}\text { Evaluated the long-term CV } \\
\text { and Gl safety of PA32540 in } \\
\text { subjects who were taking } \\
\text { aspirin } 325 \mathrm{mg}\end{array}$ & ECA plus PA3240 & $\begin{array}{l}\text { Upper GI } \\
\text { complications }\end{array}$ & [49] \\
\hline
\end{tabular}

Abbreviations: GERD, gastrointestinal reflux disease; GGA, geranylgeranylacetone; PA32540, coordinately delivered tablet consists of inner coat of 325mg ECA surrounded by an outer layer of immediate release $40 \mathrm{mg}$ omeprazole.

\section{Individual Study Results}

\section{Enteric-Coated Aspirin for GI Protection}

From 15,621 participants of the study, 9952 of the patients received an ECA of different strengths starting from $81 \mathrm{mg}$ up $325 \mathrm{mg}$. The remaining 5,669 = patients received a placebo. Almost all studies revealed that ECA treatment was not an effective mechanism against GI protection. ${ }^{20,21,23}$ However, the study from the USA stated that the use of low dose ECA has no apparent significant association in terms of ulcer development than patients enrolled in the placebo group. The incidence of ulcers in patients who received ECA was not significantly higher $(1 \%, 95 \% \mathrm{CI}, \mathrm{P}$-value 0.62$) .{ }^{19}$

Furthermore, one study reported that long term use of high dose of ECA alongside with immediate release formulation of $40 \mathrm{mg}$ omeprazole, in high risk patients for GI disease, showed that aspirin-induced upper GI injury was not associated with any new or unexpected safety events. ${ }^{24}$ Almost all the adverse events were similar with that of prior experiences with aspirin and omeprazole administration as a single agent.

\section{Long-Term Safety of Enteric-Coated Aspirin in GI Mucosa}

In the ARRIVE trial, patients using ECA suffered more from GI bleeding, epistaxis, dyspnea, GERD and upper abdominal discomfort than patients who were on a different intervention. In this study GI bleeding occurred more frequently in patients who had been allocated to the ECA group than patients assigned to the placebo group $(0.96 \%$ vs. $0.46 \%, \mathrm{HR}=2.11,95 \% \mathrm{CI}, \mathrm{P}$-value $=0.0007){ }^{23}$ Similarly most other studies also agreed that ECA do not give much GI protection when it used for both short and longer terms. For instance, in the Japanese study, it was clearly mentioned that even short-term administration of a low dose of ECA was significantly associated with an apparent small bowel injury, with the rate of $60 \%, 95 \% \mathrm{CI}$, P-value, $0.0001 .^{20}$ Another Japanese study also reported 
that low doses of aspirin resulted in damage to the walls of the small intestine. ${ }^{21}$

Current studies emphasise aspirin-induced GI damage in the presence of lower dose and enteric-coating techniques. On the other hand there are studies suggesting the use of other acid-suppressive mechanisms in the case of enteric-coated aspirin. The study from the USA revealed that when ECA is administered with omeprazole it can hugely reduce the incidence of endoscopic GI damage compared to the impact of ECA used alone. For instance the most prevalent side effect reported by this study was dyspepsia, seen in $30 \%$ of patients who received ECA and in $11 \%$ of patients who had been treated using both ECA and omeprazole (P-value 0.001). ${ }^{22}$

\section{Discussion}

This systematic review contains 6 RCTs with a total of 15,621 participants from different countries. Taking aspirin everyday was thought to be a convenient way to prevent a heart attack, stroke or other cardiovascular event. According to the American College of Cardiology and the American Heart Association, aspirin must be used for people with the highest cardiovascular risk and the lowest risk of bleeding and avoids its usage in those who are above age 70 and in those individuals with a high risk for bleeding, such as patients with chronic renal disease or thrombocytopenia. ${ }^{25}$

Almost all of the studies showed that the use of ECA does not have additional benefit towards GI protection. For instance, in the US study, the most common cause for study termination by participants who were taking a combination of ECA and omeprazole, due to adverse events, was GI complications ${ }^{24}$ and this combination enormously reduce the incidence of endoscopic GI damage compared to the impact of ECA use alone. ${ }^{22}$

Other studies reported in 2008 and 2010 from Japan indicated that a low dose of ECA was highly associated with small bowel injury ${ }^{20,21}$ and again, the ARRIVE trial demonstrated that the overall occurrence of adverse events which are associated to treatment were low in the placebo group compared to ECA. ${ }^{23}$ Four of the clinical trials involved in this review included a large number of participants with a comparison group. In addition, the participants and investigators were masked to treatment provision. These things make the study more reliable and strengthen the evidence.

This review has similar results with other studies regarding safety of ECA in GI mucosa. A retrospective cohort study showed that the occurrence of GI bleeding is not affected by the formulation of aspirin; and in patients who are on long-term low dose aspirin, ECA appears to cause small bowel bleeding that resulted in clinically significant anemia ${ }^{9}$ since it has a direct and detectable effect on the small bowel. ${ }^{20,21}$ Additionally, the degree of this small bowel mucosal injury was greater in elderly patients taking ECA than middle-aged patients. ${ }^{10}$ In another case control study, the risk of upper GI complications was similar for both ECA and non-ECA. So, the authors concluded that the coating did not adjust the effect of aspirin. ${ }^{18}$

On the other hand, a prospective cohort study done in Korea revealed that low-dose ECA alone did not cause GI bleeding in patients with coronary artery disease. ${ }^{2}$ A systematic review was prepared in 2002 by reviewing clinical trials done between 1980 and 1998 with the aim of assessing the findings on the use of different aspirin formulations and their consequences on the gastric mucosa. On this study, ECA causes significantly less mucosal damage than buffered or plain aspirin. ${ }^{7}$

According to another review carried out in 2007, there is a reduction of gastric mucosal injury with enteric coating formulation based on the results of five clinical trials even though it did not include studies carried out on old age individuals who were taking low doses of aspirin for extended periods. $^{15}$

\section{Limitations}

There were some limitations on this systematic review, like publication bias. It includes publications only written in English, because of this 58 articles were excluded after the initial search. Additionally, the inclusion of only a small number of clinical trials made it difficult to reach robust results which would be applicable to the wider population.

\section{Conclusions}

Aspirin is widely used for the prevention and treatment of cardiovascular disease. But it harms the GI mucosa by its local and systemic effects, leading to erosion, ulceration, and bleeding. To solve this problem an enteric-coated formulation of aspirin was designed. However the finding of this review concluded that almost all trials demonstrated that ECA treatment is not an effective mechanism for GI protection and it is highly associated with small bowel injury. Therefore, the coating does not reduce risk of GI complications. 


\section{Abbreviations}

ECA, enteric coated aspirin; GI, gastrointestinal.

\section{Data Sharing Statement}

All the data and materials used in this paper are available from the corresponding author upon reasonable request.

\section{Acknowledgment}

The authors would like to acknowledge all cited authors for their contribution in the field of this research area.

\section{Funding}

There is no funding to report.

\section{Disclosure}

The authors report no conflicts of interest.

\section{References}

1. Cryer B, Mahaffey KW. Gastrointestinal ulcers, role of aspirin, and clinical outcomes: pathobiology, diagnosis, and treatment. J Multidiscip Healthc. 2014;7:137-146. doi:10.2147/JMDH.S54324

2. Choi CK, Kim N, Choi JW, et al. Effect of low-dose, enteric coated aspirin on gastrointestinal bleeding in patients with coronary artery disease. Gut Liver. 2008;2(2):99-104. doi:10.5009/gnl.2008.2.2.99

3. Laine L. Review article: gastrointestinal bleeding with low-dose aspirin - what's the risk? Aliment Pharmacol Ther. 2006;24 (6):897-908. doi:10.1111/j.1365-2036.2006.03077.x

4. García Rodríguez LA, Lanas A, Soriano-Gabarró M, Cea Soriano L. Low-dose aspirin and risk of upper/lower gastrointestinal bleeding by bleed severity: a cohort study with nested case-control analysis using primary care electronic health records from the United Kingdom. Ann Med. 2019;51(2):182-192. doi:10.1080/07853890.2019.1591635

5. Chen X, Gao F, Zhang J. Screening for gastric and small intestinal mucosal injury with magnetically controlled capsule endoscopy in asymptomatic patients taking enteric-coated aspirin. Gastroenterol Res Pract. 2018;2018:1-6. doi:10.1155/2018/2524698

6. Huang ES, Strate LL, Ho WW, Lee SS, Chan AT, Prospective A. Study of aspirin use and the risk of gastrointestinal bleeding in men. PLoS One. 2010;5(12):e15721.

7. Banoob DW, Banoob DW, McCloskey WW, Webster W. Risk of gastric injury with enteric-versus nonenteric-coated aspirin. Ann Pharmacother. 2002;36(1):163-166. doi:10.1345/aph.18325

8. Lavie CJ, Howden CW, Scheiman J, Tursi J. Upper gastrointestinal toxicity associated with long-term aspirin therapy: consequences and prevention. Curr Probl Cardiol. 2017;42(5):146-164. doi:10.1016/j. cpcardiol.2017.01.006

9. Hirata Y, Kataoka H, Shimura T, et al. Incidence of gastrointestinal bleeding in patients with cardiovascular disease: buffered aspirin versus enteric-coated aspirin. Scand J Gastroenterol. 2011;46(78):803-809. doi:10.3109/00365521.2011.568522

10. Gao F, Chen X, Zhang J. Prevalence of gastric and small-intestinal mucosal injury in elderly patients taking enteric-coated aspirin by magnetically controlled capsule endoscopy. Gastroenterol Res Pract. 2019;2019:1-5. doi:10.1155/2019/9190367
11. Lanas A, Scheiman J. Low-dose aspirin and upper gastrointestinal damage: epidemiology, prevention and treatment. Curr Med Res Opin. 2007;23(1):163-173. doi:10.1185/030079907X162656

12. Newton JL. Improving the gastrointestinal tolerability of aspirin in older people. Clin Interv Aging. 2006;1(1):33-39. doi:10.2147/ ciia.2006.1.1.33

13. Huang ES, Strate LL, Ho WW, Lee SS, Chan AT. Long-term use of aspirin and the risk of gastrointestinal bleeding. Am J Med. 2011;124 (5):426-433. doi:10.1016/j.amjmed.2010.12.022

14. Goldstein JL, Scheiman JM, Fort JG, Whellan DJ. Aspirin use in secondary cardiovascular protection and the development of aspirin-associated erosions and ulcers. J Cardiovasc Pharmacol. 2016;68(2):121-126. doi:10.1097/FJC.0000000000000387

15. Walker J, Robinson J, Stewart J, Jacob S. Best evidence topic coronary does enteric-coated aspirin result in a lower incidence of gastrointestinal complications compared to normal aspirin? Interact Cardiovasc Thorac Surg. 2007;6:519-522.

16. Chowdhury A, Ganguly G, Chowdhury D, Santra A, Gupta JD, Roy T. Gastro-duodenal mucosal changes associated with low-dose aspirin therapy: a prospective, endoscopic study. Indian J Gastroenterol. 2001;20(6):227-229.

17. Törüner M. Aspirin and gastrointestinal toxicity. Anadolu Kardiyol Derg. 2007;7(SUPPL. 2):27-30.

18. de Abajo FJ, García Rodríguez LA. Risk of upper gastrointestinal bleeding and perforation associated with low-dose aspirin as plain and enteric-coated formulations. BMC Clin Pharmacol. 2001;1:1-8. doi:10.1186/1472-6904-1-1

19. Laine L, Maller ES, Yu C, Quan H, Simon T. Ulcer formation with low-dose enteric-coated aspirin and the effect of COX-2 selective inhibition: a double-blind trial. Gastroenterology. 2004;127 (2):395-402. doi:10.1053/j.gastro.2004.05.001

20. Shiotani A, Haruma K, Nishi R, et al. Randomized, double-blind, pilot study of geranylgeranylacetone versus placebo in patients taking low-dose enteric-coated aspirin. Low-dose aspirin-induced small bowel damage. Scand J Gastroenterol. 2010;45(3):292-298. doi:10.3109/00365520903453182

21. Watanabe T, Sugimori S, Kameda N, et al. Small bowel injury by low-dose enteric-coated aspirin and treatment with misoprostol: a Pilot Study. Clin Gastroenterol Hepatol. 2008;6(11):1279-1282. doi:10.1016/j.cgh.2008.06.021

22. Whellan DJ, Goldstein JL, Cryer BL, et al. PA32540 (a coordinated-delivery tablet of enteric-coated aspirin $325 \mathrm{mg}$ and immediate-release omeprazole $40 \mathrm{mg}$ ) versus enteric-coated aspirin $325 \mathrm{mg}$ alone in subjects at risk for aspirin-associated gastric ulcers: results of two 6-month, Phase 3 studies. Am Heart J. 2014;168 (4):495-502.e4. doi:10.1016/j.ahj.2014.05.017

23. Gaziano JM, Brotons C, Coppolecchia R, et al. Use of aspirin to reduce risk of initial vascular events in patients at moderate risk of cardiovascular disease (ARRIVE): a randomised, double-blind, placebo-controlled trial. Lancet. 2018;392(10152):1036-1046. doi:10.1016/S0140-6736(18)31924-X

24. Goldstein JL, Whellan DJ, Scheiman JM, et al. Long-term safety of a coordinated delivery tablet of enteric-coated aspirin $325 \mathrm{mg}$ and immediate-release omeprazole $40 \mathrm{mg}$ for secondary cardiovascular disease prevention in patients at GI risk. Cardiovasc Ther. 2016;34 (2):59-66. doi:10.1111/1755-5922.12172

25. 2019 ACC/AHA guideline on the primary prevention of cardiovascular disease - American College of Cardiology [Internet]; [cited May 6, 2020]. Available from: https://www.acc.org/latest-in-cardiology/tenpoints-to-remember/2019/03/07/16/00/2019-acc-aha-guideline-onprimary-prevention-gl-prevention. Accessed August 10, 2021. 


\section{Publish your work in this journal}

The International Journal of General Medicine is an international, peer-reviewed open-access journal that focuses on general and internal medicine, pathogenesis, epidemiology, diagnosis, monitoring and treatment protocols. The journal is characterized by the rapid reporting of reviews, original research and clinical studies across all disease areas. The manuscript management system is completely online and includes a very quick and fair peer-review system, which is all easy to use. Visit http://www.dovepress.com/ testimonials.php to read real quotes from published authors.

Submit your manuscript here: https://www.dovepress.com/international-journal-of-general-medicine-journal 